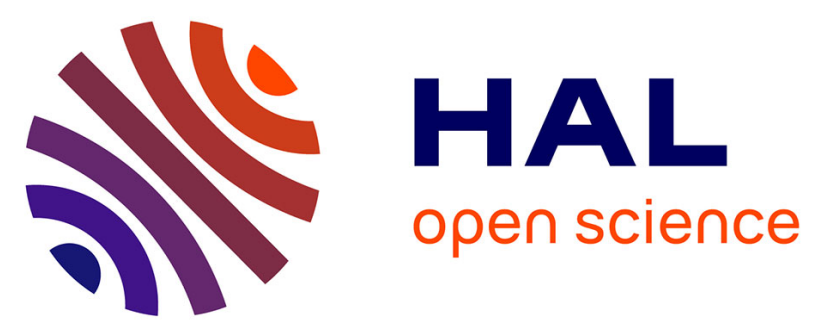

\title{
The c.156_157insAlu rearrangement accounts for more than one-fourth of deleterious BRCA mutations in northern/central Portugal
}

Ana Peixoto, Catarina Santos, Patrícia Rocha, Manuela Pinheiro, Sofia Príncipe, Deolinda Pereira, Helena Rodrigues, Fernando Castro, Joaquim Abreu, Leonor Gusmão, et al.

\section{To cite this version:}

Ana Peixoto, Catarina Santos, Patrícia Rocha, Manuela Pinheiro, Sofia Príncipe, et al.. The c.156_157insAlu rearrangement accounts for more than one-fourth of deleterious BRCA mutations in northern/central Portugal. Breast Cancer Research and Treatment, 2008, 114 (1), pp.31-38. 10.1007/s10549-008-9978-4 . hal-00478331

\section{HAL Id: hal-00478331 \\ https://hal.science/hal-00478331}

Submitted on 30 Apr 2010

HAL is a multi-disciplinary open access archive for the deposit and dissemination of scientific research documents, whether they are published or not. The documents may come from teaching and research institutions in France or abroad, or from public or private research centers.
L'archive ouverte pluridisciplinaire HAL, est destinée au dépôt et à la diffusion de documents scientifiques de niveau recherche, publiés ou non, émanant des établissements d'enseignement et de recherche français ou étrangers, des laboratoires publics ou privés. 


\title{
The c.156_157insAlu BRCA2 rearrangement accounts for more than one-fourth of deleterious BRCA mutations in northern/ central Portugal
}

\author{
Ana Peixoto - Catarina Santos · Patrícia Rocha - Manuela Pinheiro · \\ Sofia Príncipe $\cdot$ Deolinda Pereira $\cdot$ Helena Rodrigues $\cdot$ Fernando Castro $\cdot$ \\ Joaquim Abreu · Leonor Gusmão · António Amorim · Manuel R. Teixeira
}

Received: 11 March 2008/ Accepted: 13 March 2008/Published online: 25 March 2008

(C) Springer Science+Business Media, LLC. 2008

\begin{abstract}
We evaluated the contribution of an Alu insertion in BRCA2 exon 3 (c.156_157insAlu) to inherited predisposition to breast/ovarian cancer in 208 families originated mostly from northern/central Portugal. We identified the c.156_157insAlu BRCA2 mutation in 14 families and showed that it accounts for more that onefourth of deleterious BRCA1/BRCA2 mutations in breast/ ovarian cancer families originated from this part of the country. This mutation originates $B R C A 2$ exon 3 skipping and we demonstrated its pathogenic effect by showing that the $B R C A 2$ full length transcript is derived only from the wild type allele in carriers, that it is absent in 262 chromosomes from healthy blood donors, and that it
\end{abstract}

A. Peixoto - C. Santos · P. Rocha - M. Pinheiro - S. Príncipe . M. R. Teixeira ( $\square)$

Department of Genetics, Portuguese Oncology Institute, Rua Dr. António Bernardino de Almeida, 4200-072 Porto, Portugal

e-mail: mteixeir@ipoporto.min-saude.pt

D. Pereira $\cdot$ H. Rodrigues

Department of Medical Oncology, Portuguese Oncology

Institute, Porto, Portugal

F. Castro - J. Abreu

Department of Surgical Oncology, Portuguese Oncology

Institute, Porto, Portugal

L. Gusmão · A. Amorim

Institute of Molecular Pathology and Immunology, University of Porto (IPATIMUP), Porto, Portugal

A. Amorim

Faculty of Sciences, University of Porto, Porto, Portugal

M. R. Teixeira

Institute of Biomedical Sciences (ICBAS), University of Porto,

Porto, Portugal co-segregates with the disease. Polymorphic microsatellite markers were used for haplotype analysis in three informative families. In two of the three families one haplotype was shared for all but two markers, whereas in the third family all markers telomeric to BRCA2 differed from that observed in the other two. Although the c.156_157insAlu BRCA2 mutation has so far only been identified in Portuguese breast/ovarian cancer families, screening of this rearrangement in other populations will allow evaluation of whether or not it is a population-specific founder mutation and a more accurate estimation of its distribution and age.

Keywords c.156_157insAlu BRCA2 mutation . Breast cancer $\cdot$ Hereditary predisposition

\section{Introduction}

Molecular analyses of the BRCA1 and BRCA2 genes in families suspected to have hereditary predisposition to breast/ovarian cancer have shown that most populations exhibit a wide spectrum of mutations throughout both genes. However, several founder mutations have been identified in individuals of different ancestries, including those of Ashkenazi Jewish (185delAG and 53832insC) [1], French Canadian (C4446T and 2953del3+C) [2, 3], Norwegian (1675delA and 1135insA) [4], Dutch (2804delAA and Alu-mediated deletions encompassing exons 13 and 22) [5, 6], Polish (5382insC, C61G, and 4153delA) [7], Greek (5382insC and G1738R) [8, 9], Icelandic (999del5) [10], Spanish (330A>G, 6857_6858del, and 9254_9258del) [11, 12], and Swedish (3171ins5) [13] origins. We have previously reported several novel mutations in a first characterization of the mutational spectrum of the entire coding sequences and exon-intron boundaries of the 
$B R C A 1$ and $B R C A 2$ genes and large $B R C A 1$ rearrangements in Portuguese breast/ovarian cancer families [14].

Recently, Teugels et al. [15] identified an Alu insertion in BRCA2 exon 3 (c.156_157insAlu) in a Portuguese breast cancer patient living in Belgium. This mutation was not detectable using the conventional mutation screening techniques and originates skipping of BRCA2 exon 3 [15]. A regional founder effect has recently been described for this rearrangement in hereditary breast/ovarian cancer families mostly originated from central/southern Portugal [16]. In an attempt to gain insight into the ancestral origin and population spread of the c.156_157insAlu BRCA2 mutation, we estimated its frequency in breast/ovarian cancer families originated mostly from northern/central Portugal and analyzed the chromosomal background upon which this mutation occurs using 10 microsatellite markers surrounding the BRCA2 gene. Furthermore, because some doubts have been raised about the pathogenic effect of $B R C A 2$ exon 3 skipping [17], we have performed segregation studies and mRNA expression analysis of c.156_157insAlu carriers and disease-free controls.

\section{Materials and methods}

\section{Patients}

This study comprised the 78 Portuguese breast/ovarian cancer families in whom no clearly deleterious BRCAI/ $B R C A 2$ mutations were found in our previous study [14] and an additional $130 \mathrm{BRCA} / \mathrm{BRCA} 2$ negative probands that had been selected using the following the criteria: (1) families with one or more breast cancers (one of them diagnosed before the age of 50 years) and one or more ovarian cancers (BC $+\mathrm{OC})$; (2) families with two or more female breast cancers, one of them diagnosed before the age of 50 years ( $\geq 2 \mathrm{BC}$ ); (3) families with at least one case of breast cancer or ovarian cancer in association with at least one case of male breast cancer (MBC); (4) patients without family history of breast/ovarian cancer, but showing early-onset breast cancer (1BC, diagnosed before the age of 35 years), breast (diagnosed before the age of 60 years) and ovarian cancer $(1 \mathrm{BC}+\mathrm{OC})$, bilateral breast carcinomas (1BlC, one of them diagnosed before the age of 50 years), or male breast cancer (1MBC, at any age). BRCAPRO mutation probabilities were estimated for all probands [18].

DNA isolation and BRCA1/BRCA2 mutation screening

Genomic DNA was extracted from peripheral leucocytes according to standard procedures and subsequently amplified using primers described by van der Hout et al. [19]. Mutation screening of the entire coding regions of $B R C A 1$ and BRCA2 was performed by Denaturing Gradient Gel Electrophoresis (DGGE), using the IngenyphorU system (Ingeny; Goes). Sequence analysis of genomic fragments with altered DGGE mobility pattern was carried out on an Applied Biosystems' 310 automated DNA sequencer (Foster City), using the dye terminator method. Multiplex Ligation-dependent Probe Amplification (MLPA) (MRC-Holland, Amsterdam) was used to detect large exonic BRCA1 and BRCA2 rearrangements (only 23 probands were analyzed for the latter gene) in cases that were negative for pathogenic BRCA1/BRCA2 point mutations.

Screening for the c.156_157insAlu BRCA2 mutation

The c.156_157insAlu BRCA2 mutation was screened in 208 probands and in 262 control chromosomes (healthy blood donors). In the first PCR we used primers for $B R C A 2$ exon 3 amplification (forward primer: GTCACTGGT TAAAACTAAGGTGGG and reverse primer: GAAGCCA GCTGATTATAAGATGGTT). The cycling conditions were $94^{\circ} \mathrm{C}$ for $1 \mathrm{~min}, 35$ cycles of $94^{\circ} \mathrm{C}$ for $1 \mathrm{~min}, 52^{\circ} \mathrm{C}$ for $1 \mathrm{~min}$, and $72^{\circ} \mathrm{C}$ for $4 \mathrm{~min}$, and a final extension of $72^{\circ} \mathrm{C}$ for $10 \mathrm{~min}$. In the second PCR we used primers specific for the c.156_157insAlu BRCA2 mutation (forward primer: GACACCATCCCGGCTGAAA and reverse primer: CCC CAGTCTACCATATTGCAT). The cycling conditions were $97^{\circ} \mathrm{C}$ for $15 \mathrm{~min}, 6$ cycles of $97^{\circ} \mathrm{C}$ for $1 \mathrm{~min}, 68^{\circ} \mathrm{C}$ for $1 \mathrm{~min}$, and $72^{\circ} \mathrm{C}$ for $1 \mathrm{~min}, 6$ cycles of $97^{\circ} \mathrm{C}$ for $1 \mathrm{~min}$, $66^{\circ} \mathrm{C}$ for $30 \mathrm{~s}$, and $72^{\circ} \mathrm{C}$ for $1 \mathrm{~min}, 6$ cycles of $97^{\circ} \mathrm{C}$ for $1 \mathrm{~min}, 64^{\circ} \mathrm{C}$ for $30 \mathrm{~s}$, and $72^{\circ} \mathrm{C}$ for $1 \mathrm{~min}, 22$ cycles of $97^{\circ} \mathrm{C}$ for $1 \mathrm{~min}, 60^{\circ} \mathrm{C}$ for $30 \mathrm{~s}$, and $72^{\circ} \mathrm{C}$ for $1 \mathrm{~min}$, and a final extension of $72^{\circ} \mathrm{C}$ for $10 \mathrm{~min}$. Sequence analysis of genomic fragments with the insertion was carried out on an Applied Biosystems' 310 automated DNA sequencer (FosterCity), using the dye terminator method.

RNA isolation and transcript analysis

Frozen cell pellets from nucleated cells of patients carrying the c.155_156insAlu BRCA2 variant and from control individuals (without known BRCA1 or BRCA2 mutations) were used to extract total RNA using $1 \mathrm{ml}$ of Tripure isolation reagent (Roche Diagnostics, Indianapolis, USA), according to the manufacturer's instructions. After quantification using a NanoDrop ND-1000 spetrophotometer, One-Step RT-PCR was performed in all cases using the Superscript One-Step RT-PCR System as suggested by the manufacturer (Invitrogen, Carlsbad, USA). We used primers spanning from exon 1 to exon 6 of BRCA2 (forward primer B2Ex1F: GCTTACTCCGGCCAAAAAAGA and reverse 
primer B2Ex6R: GGTGTCTGACGACCCTTCACA). The cycling conditions were $50^{\circ} \mathrm{C}$ for $30 \mathrm{~min}, 95^{\circ} \mathrm{C}$ for $15 \mathrm{~min}$, 40 cycles of $94^{\circ} \mathrm{C}$ for $30 \mathrm{~s}, 55^{\circ} \mathrm{C}$ for $1 \mathrm{~min}$, and $72^{\circ} \mathrm{C}$ for $1 \mathrm{~min}$, and a final extension of $72^{\circ} \mathrm{C}$ for $10 \mathrm{~min}$. RT-PCR products were separated on a $2 \%$ agarose gel (SeaKem LE Agarose, Rockland, USA) and visualized with ethidium bromide in an image analyser ImageMaster VDS (Amersham Biosciences, Little Chalfont, UK). Individual bands were excised from the gel, purified using $\mathrm{GFX}^{\mathrm{TM}}$ PCR DNA and Gel Band Purification Kit (GE HealthCare) and sequenced as indicated above.

Microsatellite typing and haplotype analysis

A total of 14 probands and 14 family members were genotyped for polymorphic microsatellite markers flanking $B R C A 2$ and for the c. $-25 \mathrm{G}>\mathrm{A}$ polymorphism. The order of the markers, the consensus repeat, and the distances relative to each other and BRCA2 are shown in Table 1. The physical distances of the genetic markers were derived from the Human Genome Browser assembly hg18 from the UCSC Genome Bioinformatics (http://www.genome.ucsc.edu/). The consensus pattern was obtained with the software Tandem Repeats Finder (http://www.tandem.bu.edu/). The primer sequences for the amplification of the markers were derived from the Human Genome database (http:// www.gdb.org). All 10 markers were assayed by PCR using fluorescently end-labeled primers. PCR products were run on an ABI PRISM 310 Genetic Analyser (Applied Biosystems) together with a fluorescence labeled DNA fragment size standard. Genotyping of the c.-25G $>$ A polymorphism was performed by sequencing. Haplotypes were reconstructed manually in the three informative families. The geographic origin of the c.156_157insAlu BRCA2 positive families was inferred from the birthplace of the oldest carrier or of the oldest affected family member most likely to be a carrier.

\section{Results}

Detection of the c.156_157insAlu BRCA2 mutation

We identified eight probands with the c.156_157insAlu mutation in our initial series of 78 patients in whom no deleterious BRCA1/BRCA2 mutation had been found by DGGE and MLPA. This finding, together with the 22 pathogenic mutations previously reported [14], raised the deleterious mutation detection rate to $30 \%$ (30/100) of all cases studied and to $37 \%$ (29/79) of those probands with a family history of breast/ovarian cancer. The c.156_157ins Alu BRCA2 mutation accounts for $27 \%$ of the 30 probands with $B R C A 1 / B R C A 2$ pathogenic mutations and

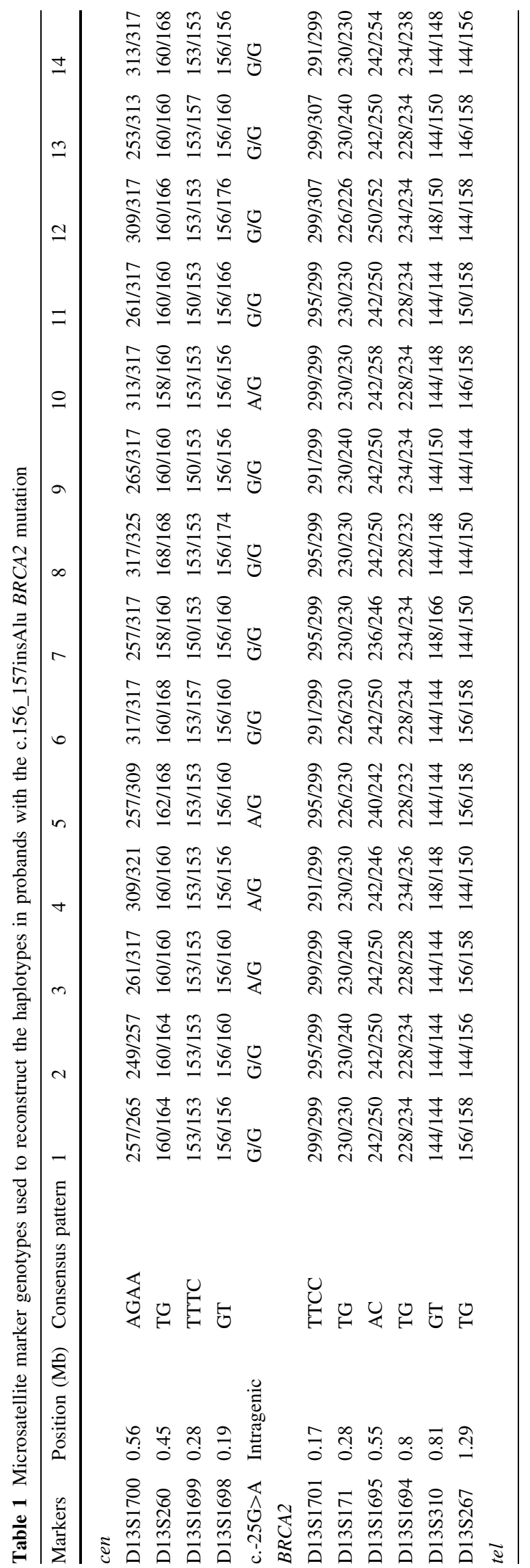


$53 \%$ of the 15 deleterious $B R C A 2$ mutations identified in that series of 100 probands from breast/ovarian cancer families. Furthermore, screening of the c.156_157insAlu BRCA2 mutation in 130 additional probands in whom no germline BRCA1/BRCA2 mutations have been detected by DGGE and MLPA (data not shown) revealed six additional families with this mutation. Of the 14 probands with the c.156_157insAlu $B R C A 2$ mutation, eight belonged to $\geq 2 \mathrm{BC}$ families, three to MBC families, two to $\mathrm{BC}+\mathrm{OC}$ families, and one was a $1 \mathrm{BC}+\mathrm{OC}$ patient. The mutation was also detected in six affected family members but neither in eight healthy relatives nor in the 262 chromosomes of the control population.

\section{Analysis of RNA transcripts}

RNA splicing was evaluated by amplifying the BRCA2 coding region from exon 1 through exon 6 . When the products from these reactions were visualized on agarose gels, besides a normal transcript two shorter bands were common to both the patients and controls: a transcript representing an in frame skip of exon 3 (BRCA2- $\triangle \mathrm{ex} 3)$ and a transcript with deletion of exon 3 plus 109 bp of exon 4 (Fig. 1). However, the band representing the BRCA2- $\triangle \mathrm{ex} 3$ transcript had much higher intensity in the patients with the c.156_157insAlu BRCA2 mutation. When these fragments were excised from the gel, amplified, and sequenced, and because the PCR were designed to generate fragments that contained the c. $-25 \mathrm{G}>\mathrm{A}$ polymorphism, we could demonstrate that the controls heterozygous for the c.-25G $>A$ polymorphism showed heterozygosity in the full length and the $B R C A 2-\triangle \operatorname{ex} 3$ transcripts, whereas the patients heterozygous for that polymorphism presented mainly one allele in the full length transcript and the other allele in the $B R C A 2-\Delta \mathrm{ex} 3$ transcript (Fig. 1). These findings indicate that the normal mRNA for $B R C A 2$ is produced only from one chromosome in the patient.

\section{Haplotype analysis}

Haplotypes were phased for most of the markers for only three out of the 14 families. The results of the haplotype analyses for the three informative families are shown in Fig. 2. In one informative family, the haplotype associated with the mutation could be inferred accurately as five carriers were genotyped. In the other two families the haplotype was inferred in most instances as two carriers per family were genotyped. One haplotype was found to segregate within two families (11 and 13). The shared haplotype covered eight markers, but varied for the D13S1701 and D13S1700 alleles. In family 12 the disease associated alleles from the BRCA2 telomeric region were different from those associated with families 11 and 13. The genotypes found for the remaining probands are shown in Table 1 and the geographic origins of
A
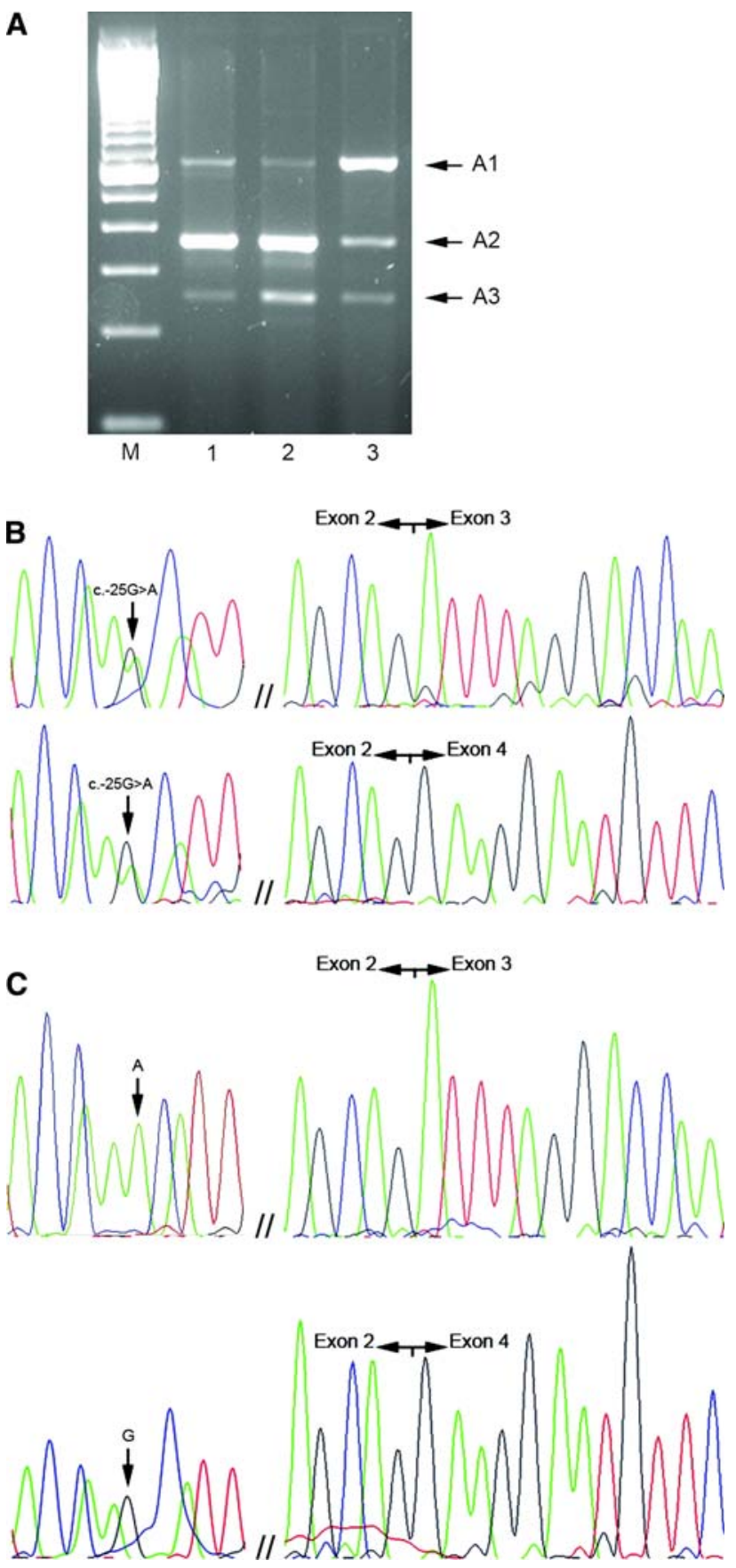

Fig. 1 RT-PCR analyses from exon 1 to exon 6 of the $B R C A 2$ gene in c.156_157insAlu BRCA2 mutation carriers and controls. (a) Lane 1, $100 \mathrm{bp}$ DNA standard. Lanes 2 and 3, patients with the c.156_157insAlu BRCA2 mutation. Lane 3, wild type control sample. A1 represents the full length transcript, $\mathrm{A} 2$ the $B R C A 2-\Delta \mathrm{ex} 3$ transcript and $A 3$ the transcript with deletion of exon 3 plus 109 bp of exon 4 (data not shown). (b) Sequencing of the RT-PCR product (A1 band top and A2 band bottom) from a control individual with the c. $-25 \mathrm{G}>$ A germline polymorphism (noted by an arrow), showing heterozygosity in the full length and the $B R C A 2-\triangle$ ex 3 transcripts. (c) Sequencing of the RT-PCR product (A1 band top and A2 band bottom) from a c.156_157insAlu $B R C A 2$ mutation carrier with the c.-25G $>$ A germline polymorphism (noted by an arrow), showing mainly one allele in the full length transcript and the other allele in the BRCA2- $\triangle \mathrm{ex} 3$ transcript 
Fig. 2 Pedigrees of the three informative breast/ovarian cancer families and haplotype results (families 11, 12 and 13 in $\mathbf{a}, \mathbf{b}$ and $\mathbf{c}$, respectively). The order of the microsatellite markers is the same as in Table 1 and the alleles that segregate with the mutation are underlined. Unaffected individuals are indicated with open symbols, patients affected with breast cancer with black symbols. Bilateral breast disease is represented by striped circles and breast/ovarian cancer patients by dotted circles. Plus and minus signals represent family members with and without the c.156_157insAlu $B R C A 2$ mutation, respectively

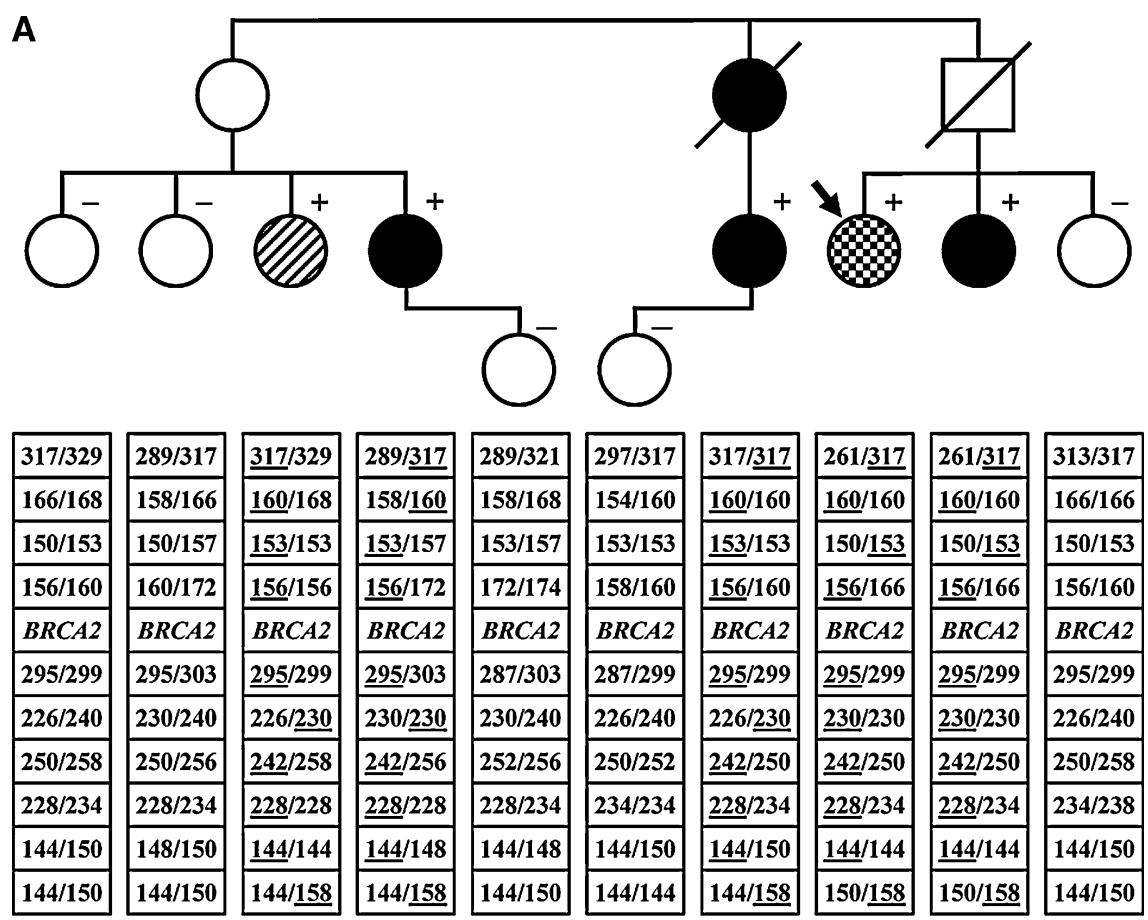

B

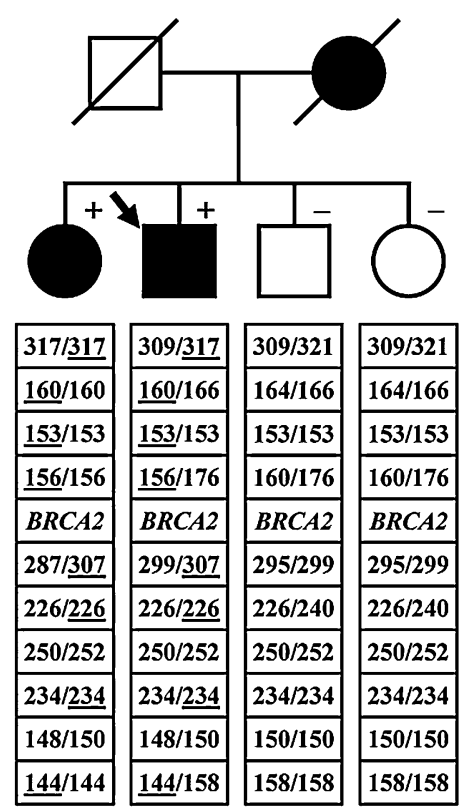

C

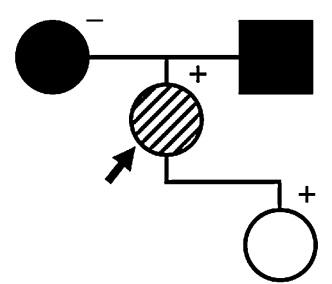

\begin{tabular}{|c|c|c|}
\hline $253 / 309$ & $53 / \underline{313}$ & $13 / 329$ \\
\hline & & \\
\hline 1 & & $\underline{53} / 153$ \\
\hline 60 & 50 & $56 / 156$ \\
\hline$B R C A 2$ & $R C A 2$ & $B R C A 2$ \\
\hline $299 / 307$ & 299/307 & $275 / \underline{299}$ \\
\hline $232 / 240$ & $\underline{230} / 240$ & $230 / 240$ \\
\hline $250 / 254$ & $\underline{242 / 250}$ & $\underline{242 / 252}$ \\
\hline $228 / 234$ & $228 / 234$ & $228 / 228$ \\
\hline $150 / 150$ & 144 & $144 / 150$ \\
\hline $146 / 156$ & $146 / \underline{158}$ & $144 / \underline{158}$ \\
\hline
\end{tabular}

the c.156_157insAlu BRCA2 positive families are shown in Fig. 3.

\section{Discussion}

Our findings show that the specific detection of the c.156_157insAlu BRCA2 mutation in Portuguese breast/ ovarian cancer families allows a significant increase in the detection rate of $B R C A 1 / B R C A 2$ mutations from $24.7 \%$ to
$37 \%$ of those with a family history of cancer. This mutation rate is slightly above what has been reported in the majority of populations using similar criteria for referral to genetic counseling and testing [12, 20-22], something that might reflect the fact that we are now able to detect a mutation that escaped conventional mutation screening techniques. If we had used more strict selection criteria like those of the other major report on BRCA1/BRCA2 analysis of Portuguese breast/ovarian cancer families (BRCAPRO risk $>25 \%$, resulting in a mutation detection rate of $36 \%$, one- 


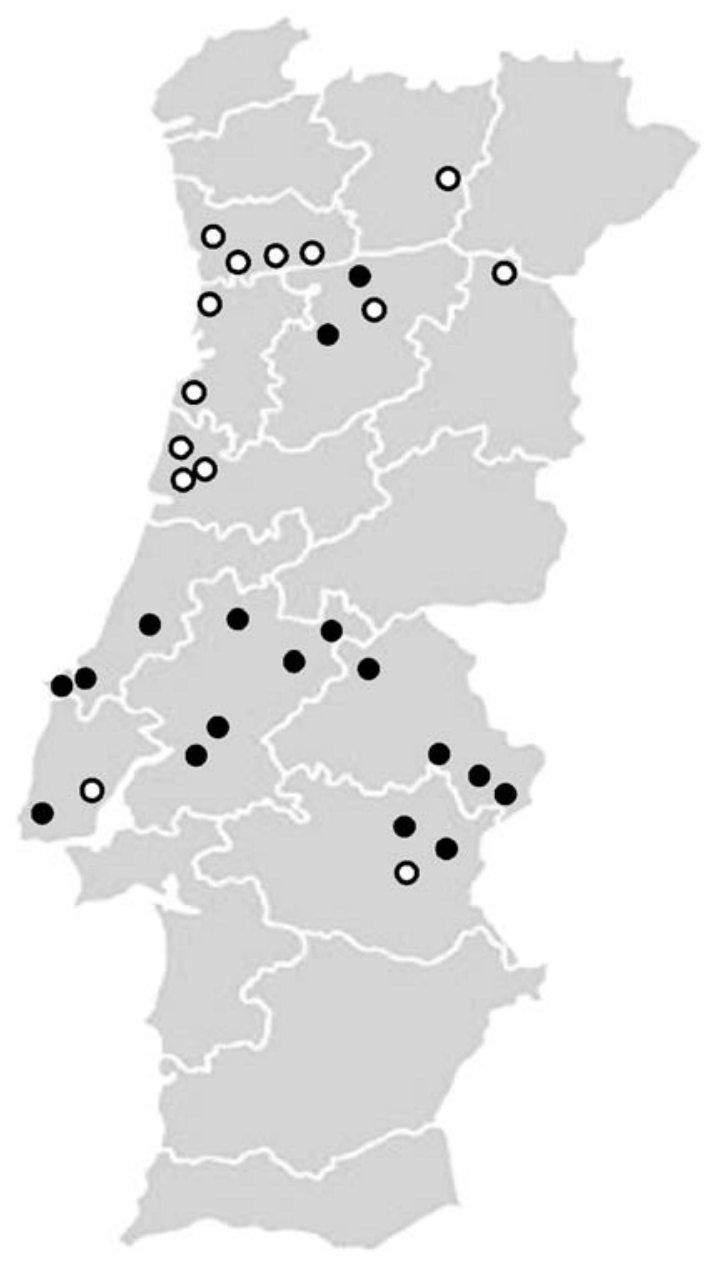

Fig. 3 Map of Portugal showing the known geographical origin of the families with the c.156_157insAlu BRCA2 germline mutation. The open circles indicate the origin of the 14 families here reported and the black circles the families previously described by Machado et al. [16]

sixth being the c.156_157insAlu BRCA2 mutation [16]), our mutation detection rate would have been $41 \%$. Although this mutation rate can be seen as relatively high, it also indicates that other BRCA1/BRCA2 mutations undetectable by current-day screening methodologies may remain to be uncovered in high-risk breast/ovarian cancer families. On the other hand, five out of the 30 pathogenic mutations would have been missed had we used the generally recommended higher that $10 \%$ mutation probability criteria for genetic testing ( 8 of 30 if $>25 \%$ ). Careful selection of families after genetic counseling is therefore recommended to increase the chance of identifying all families that can benefit from genetic diagnosis of inherited predisposition to breast/ovarian cancer.

Teugels et al. [15] demonstrated that the c.156_157ins Alu mutation originates an in-frame deletion of exon 3 from the BRCA2 mRNA encoding a transcriptional activation domain. On the other hand, Díez et al. [17] issued a word of caution when interpreting as pathogenic alterations causing $B R C A 2$ exon 3 skipping, as exon 3 splicing can also be detected in normal tissues. In order to better characterize the pathological and clinical significance of this mutation, we have looked for this mutation in disease-free controls, analyzed in more detail the mRNA in carriers and noncarriers, and reconstructed haplotypes in informative families. Three separate findings corroborate the conclusion that the c.156_157insAlu BRCA2 mutation is indeed deleterious. First, $B R C A 2$ full length transcript is derived only from the wild type allele in patients carrying the c.156_157insAlu $B R C A 2$ mutation, whereas the $B R C A 2-\triangle \mathrm{ex} 3$ transcript was transcribed mostly from the mutated allele. This was demonstrated using a heterozygous polymorphism to evaluate the relative contribution of each allele to normal and BRCA2- $\triangle \mathrm{ex} 3$ transcripts in patients and controls [23], the latter showing both alleles giving rise to a small proportion of the BRCA2- $\Delta \mathrm{ex} 3$ transcript. Second, if the abnormal transcript with the in-frame deletion of exon 3 is fully functional, as it was suggested by Díez et al. [17], then this variant would have to be considered a polymorphism given its high frequency (8\%) in families suspected to have hereditary predisposition to breast/ovarian cancer. However, we did not find the c.156_157insAlu in 262 chromosomes from healthy blood donors, allowing us to dismiss the hypothesis that it is a neutral polymorphism. Third, we could show co-segregation of this alteration and disease in six affected (but not in healthy) family members belonging to the informative families. These pieces of information allow us to confidently conclude that the c.156_157insAlu BRCA2 mutation is associated with the hereditary predisposition to breast/ovarian cancer in these families.

Alu elements are believed to insert randomly in the host genome, so the fact that this particular Alu is inserted at exactly the same position in BRCA2 exon 3 in all 14 families is by itself sufficient evidence that this represents a founder effect and not a recurrent mutation [24]. Additionally, in all c.156_157insAlu mutation carriers heterozygous for the c.-25G $>$ A polymorphism there was a physical association between the mutation and the allele that did not contribute to wild type transcript. Nevertheless, analysis of the chromosomal background upon which a mutation occurs can be used to reconstruct its origin and age. We have performed haplotype reconstruction with ten microsatellite markers in three informative families. In two of the three families one haplotype was shared for all but two markers, whereas in the third family all markers telomeric to $B R C A 2$ differed from that observed in the other two. A recombination event around $B R C A 2$ could account for the latter haplotype difference, whereas the variance in allele size of one tetranucleotide repeat unit within the D13S1701 allele in two families may have been 
caused by slippage during DNA replication of this repeat sequence. It is not possible to determine if this marker exhibits a higher mutation rate than other markers in the $B R C A 2$ region, as it was suggested by other studies [25], or if that mutation occurred early on during in the spreading of the population carrying the c.156_157insAlu BRCA2 mutation. If we compare the D13S1701 genotypes for all $14 \mathrm{c} .156$ 157insAlu positive probands, it is tempting to say that all mutation carriers with unphased genotypes harbored the same 299 allele, but in two out of three informative families we observed that this allele did not segregate with the mutation. The possibility exists that this variation in D13S1701 is more frequent than that observed by Machado et al. [16], so care should be taken when constructing haplotypes from independent families. If that is so, estimation based on the closest recombinant markers could greatly underestimate mutation age. Although Machado et al. [16] claim that the c.156_157insAlu BRCA2 mutation has it origin 2,400-2,600 years ago in what is now central/southern Portugal, it is likely that it merely reflects their target population for genetic testing. In fact, we here show that the c.156_157insAlu BRCA2 mutation accounts for $27 \%$ of the BRCA1/BRCA2 deleterious mutations in northern/central Portugal (our main target population; Fig. 3), as compared to $16 \%$ in central/ southern Portugal [16]. Although all known c.156_157insAlu BRCA2 mutations have so far been identified in Portuguese breast/ovarian cancer families, we cannot rule out that this mutation may be present in other populations and so it might have been introduced in Iberian Peninsula from somewhere else.

In summary, our study provides significantly new evidence to substantiate the pathogenicity of the c.156_157insAlu BRCA2 rearrangement and shows that this mutation is responsible for more that one-fourth of deleterious BRCAI/BRCA2 mutations in northern/central Portugal. To further evaluate whether or not it constitutes a population-specific founder mutation, one needs to perform the screening of the c.156_157insAlu BRCA2 rearrangement in other populations, which will allow for a more accurate estimation of its distribution and age.

\section{References}

1. Tonin P, Serova O, Lenoir G et al (1995) BRCA1 mutations in Ashkenazi Jewish women. Am J Hum Genet 57:189

2. Durocher F, Tonin P, Shattuck-Eidens D et al (1996) Mutation analysis of the BRCA1 gene in 23 families with cases of cancer of the breast, ovary, and multiple other sites. J Med Genet 33:814-819

3. Tonin PN, Mes-Masson AM, Futreal PA et al (1998) Founder BRCA1 and BRCA2 mutations in French Canadian breast and ovarian cancer families. Am J Hum Genet 63:1341-1351
4. Dørum A, Hovig E, Tropé C et al (1999) Three per cent of Norwegian ovarian cancers are caused by BRCA1 1675delA or1135insA. Eur J Cancer 35:779-781

5. Peelen T, Cornelis RS, van Vliet M et al (1996) The majority of 22 Dutch high-risk breast cancer families are due to either BRCA1 or BRCA2. Eur J Hum Genet 4:225-230

6. Petrij-Bosch A, Peelen T, van Vliet M et al (1997) BRCA1 genomic deletions are major founder mutations in Dutch breast cancer patients. Nat Genet 17:341-345

7. Górski B, Jakubowska A, Huzarski T et al (2004) A high proportion of founder BRCA1 mutations in Polish breast cancer families. Int J Cancer 110:683-686

8. Konstantopoulou I, Rampias T, Ladopoulou A et al (2008) Greek BRCA1 and BRCA2 mutation spectrum: two BRCA1 mutations account for half the carriers found among high-risk breast/ovarian cancer patients. Breast Cancer Res Treat 107:431-441

9. Anagnostopoulos T, Pertesi M, Konstantopoulou I et al (2007) G1738R is a BRCA1 founder mutation in Greek breast/ovarian cancer patients: evaluation of its pathogenicity and inferences on its genealogical history. Breast Cancer Res Treat. doi:10.1007/ s10549-007-9729-y

10. Rafnar T, Benediktsdottir KR, Eldon BJ et al (2004) BRCA2, but not BRCA1, mutations account for familial ovarian cancer in Iceland: a population-based study. Eur J Cancer 40:2788-2793

11. Campos B, Díez O, Odefrey F et al (2003) Haplotype analysis of the BRCA2 9254delATCAT recurrent mutation in breast/ovarian cancer families from Spain. Hum Mutat 21:452

12. Díez O, Osorio A, Durán M et al (2003) Analysis of BRCA1 and BRCA2 genes in Spanish breast/ovarian cancer patients: a high proportion of mutations unique to Spain and evidence of founder effects. Hum Mutat 22:301-312

13. Bergman A, Einbeigi Z, Olofsson U et al (2001) The western Swedish BRCA1 founder mutation 3171ins5; a $3.7 \mathrm{cM}$ conserved haplotype of today is a reminiscence of a 1500-year-old mutation. Eur J Hum Genet 9:787-793

14. Peixoto A, Salgueiro N, Santos C et al (2006) BRCA1 and BRCA2 germline mutational spectrum and evidence for genetic anticipation in Portuguese breast/ovarian cancer families. Fam Cancer 5:379-387

15. Teugels E, De Brakeleer S, Goelen G et al (2005) De novo Alu element insertions targeted to a sequence common to the BRCA1 and BRCA2 genes. Hum Mutat 26:284

16. Machado PM, Brandão RD, Cavaco BM et al (2007) Screening for a BRCA2 rearrangement in high-risk breast/ovarian cancer families: evidence for a founder effect and analysis of the associated phenotypes. J Clin Oncol 25:2027-2034

17. Díez O, Gutiérrez-Enríquez S, Ramón y Cajal T et al (2007) Caution should be used when interpreting alterations affecting the exon 3 of the BRCA2 gene in breast/ovarian cancer families. J Clin Oncol 25:5035-5036

18. Parmigiani G, Berry D, Aguilar O (1998) Determining carrier probabilities for breast cancer-susceptibility genes BRCA1 and BRCA2. Am J Hum Genet 62:145-158

19. van der Hout AH, van den Ouweland AM, van der Luijt RB et al (2006) A DGGE system for comprehensive mutation screening of BRCA1 and BRCA2: application in a Dutch cancer clinic setting. Hum Mutat 27:654-666

20. Claes K, Poppe B, Coene I et al (2004) BRCA1 and BRCA2 germline mutation spectrum and frequencies in Belgian breast/ ovarian cancer families. Br J Cancer 90:1244-1251

21. Perkowska M, BroZek I, Wysocka B et al (2003) BRCA1 and BRCA2 mutation analysis in breast-ovarian cancer families from northeastern Poland. Hum Mutat 21:553-554

22. Shih HA, Couch FJ, Nathanson KL et al (2002) BRCA1 and BRCA2 mutation frequency in women evaluated in a breast cancer risk evaluation clinic. J Clin Oncol 20:994-999 
23. Judkins T, Hendrickson BC, Deffenbaugh AM et al (2005) Single nucleotide polymorphisms in clinical genetic testing: the characterization of the clinical significance of genetic variants and their application in clinical research for BRCA1. Mutat Res 573:168-179

24. Rowold DJ, Herrera RJ (2000) Alu elements and the human genome. Genetica 108:57-72
25. Oros KK, Leblanc G, Arcand SL et al (2006) Haplotype analysis suggest common founders in carriers of the recurrent BRCA2 mutation, 3398delAAAAG, in French Canadian hereditary breast and/ovarian cancer families. BMC Med Genet 7:23 